\title{
German Physical Society
}

\section{Deutsche Physikalische Gesellschaft (DPG)}

\author{
President :
}

\author{
Secretary : K.-H. Riewe \\ D - 645 Hanau, \\ Heraeusstr. 12-14 \\ (Address of the Society)
}

The German Physical Society had its origin in Berlin. On 14 January 1845 a "Physical Society of Berlin" (Physikalische Gesellschaft zu Berlin) was founded by six young physicists. The oldest of them, E. du BoisReymond, was only 27 years old - he later became Chairman of the Society and, in 1888, its first Honorary President. The young physicists were co-workers of the Assistant Professor (Privatdozent) Gustav Magnus, "already 43 years old"', who became a member of the Society only some time later. It sounds rather modern that the young colleagues founded an association without the co-operation of their established teacher!

Only one week after the foundation, the first scientific session was held. One year later, there were already 53 names on the membership list, including those of Hermann Helmholtz and the "Lieutenant" Werner Siemens. At a session of the Society in 1866, Siemens demonstrated his dynamoelectrical principle for the first time.

As the number of members residing outside Berlin grew, the Society became a "German Physical Society" (DPG) in 1899. During sessions of the DPG, Max Planck reported on his radiation law in 1899 and Max von Laue on interference in crystals in 1912. In 1920 a "German Society for Technical Physics" (Deutsche Gesellschaft für Technische Physik) was founded. Both Societies existed until the end of World War II in 1945. After the war, several Physical Societies, one for each occupied zone in Germany, were founded by members of both former Societies. The Societies in the Western part of Germany and West-Berlin became united in 1951, and in 1963 they accepted the old name "German Physical Society". The regional Societies founded first, became five Regional Branches ( $R e-$ gionalverbände) of the DPG.

Any person or firm residing inside or outside Germany and seriously interested in physics may become an ordinary member of DPG. Applica- tions for membership must be supported by a person who is already a member of DPG and have to be sent to the Secretary. There are also honorary members.

In 1967 the number of members was about 5600 including about 900 students, 320 physics teachers, and 200 industrial companies, scientific institutes, etc. About 450 members reside outside Germany. Nearly half of the personal members with at least a "Diplom-Physiker" degree are working in industry. The membership fee for students is DM 6, for those members in normal employment DM 42 , for industrial companies not less than DM 150 per year. These fees include charges for the affiliation of the DPG to the EPS.

Until October 1969 the Board (Vorstand) is
President
: M. Kersten, Braunschweig
Vice President : A. Scharmann, Giessen
Treasurer
: A. Lompe, Munich (Osram)
Board Members : E. Lüscher, Munich
K. Räntsch, Oberkochen (Carl Zeiss)
E. Richter, Frankfort (AEG-Tele- funken)
P. Stähelin, Hamburg.

The President Designate for 1969 to 1971 is K. Ganzhorn, Böblingen (IBM Deutschland). The DPG constitution prescribes that each alternate President shall be a physicist working in industry ; the present Board Members from industry are indicated above.

There is also an Executive Council (Vorstandsrat) which consists of the Board Members, the five Chairmen of the Regional Branches, three Chairmen of Professional (or Special) Groups, the past Presidents, and representatives of Associated Societies.
In conversation at a meeting of the German Physical Society (left to right) $H$. Schmid (President of the Austrian Academy of Science), M. Kersten (President of the DPG from 19661968), and H. Hanle (Giessen).
An Association Relationship exists between DPG and the German Geophysical Society (Deutsche Geophysikalische Gesellschaft), the German Society for Biophysics (Deutsche Gesellschaft für Biophysik), the German Society for Applied Optics (Deutsche Gesellschaft für Angewandte Optik), the Union of German Meteorological Societies (Verband Deutscher Meteorologischer Gesellschaften), and Societies of physics teachers. The aims of this relationship are: coordination of meetings, exchange of teaching experience in schools and universities, collaboration in all questions concerning high school reform, regulations for academic examinations, etc. By the participation of the mentioned representatives in the sessions of the Executive Council of DPG and of DPG representatives in the councils of the other Societies, everyone is aware of problems concerning all Societies and activities can be coordinated.

Special Divisions or Professional Groups (Fachausschüsse) deal with the following topics: Nuclear Physics and Cosmic Rays (including Elementary Particles), High-Frequency Physics, Acoustics, Low Temperatures, High-Polymer Physics, Plasma and Gas Discharge Physics, Semi conductor Physics, Vacuum Physics, Physics of a Ultra-rapid Phenomena, Thermodynamics and Statistical Mechanics, Electronics in Physical Experiments, Molecular Physics.

To avoid establishing societies for each field partially or fully covered by the existing Societies, the DPG sponsors in collaboration with other Societies, the following Common Working Groups (Arbeitsgemeinschaften) :

Extra-terrestrial Physics (in collaboration with the Societies of geophysicists, meteorologists, and astronomers)

Metal Physics (with metallurgists and steelmakers)

Magnetism (with electrical engineers, metallurgists, and steelmakers)

Vacuum (with engineers, chemists, and communications engineers) 


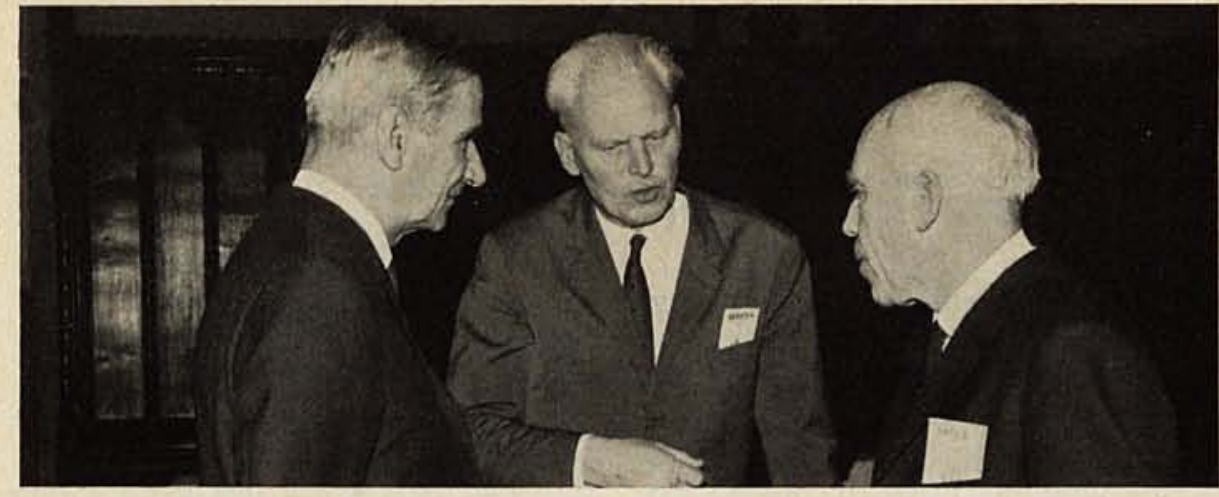

Computers (with mathematicians, electrical engineers, etc.)

Cybernetics (with ten other Societies)

Mass Spectroscopy (with chemists and physical chemists)

Irradiation Effects and Protection (with biophysicists)

Physics of Ceramics and Glass (with two societies dealing with ceramics and glass)

Physical Optics (with the German Society for Applied Optics).

DPG Committees deal with special matters such as symbols, units and nomenclature, education, documentation, publications, problems of the profession and different employments of physicists (with the exception of salaries and related problems handled by different trade unions), circle of leading or managing physicists in industry (Gesprächskreis der Industriephysiker), etc.

The Regional Branches organize yearly Spring Sessions in which one or more Professional Groups participate. Thus the five Spring Sessions are more or less specialized. Every year the DPG arranges a large Conference of Physicists of five days. The 34th Conference of Physicists will be held from 29 September to 4 October 1969 at Salzburg (Aústria) together with the Austrian Physical Society, the German Geophysical Society, and the German Society for Applied Optics.

The aims of these Conferences are : to demonstrate the importance and fundamental role of physics and natural sciences to the public, governmental authorities, etc.

to bring together physicists of all professional branches (industry, universities, research institutes) and of all fields of physics (fundamental or applied research in electro-technology, chemistry, steelmaking, etc.)

to demonstrate the unity of physics, from theoretical physics on one hand to the applications in industries on the other, and to show that all physicists can speak the same language and understand each other.
The Conferences of Physicists consist of Plenary Lectures which aim to cover, in the course of several years, all branches of physics and neighbouring fields of science. These lectures are intended to be understood by most physicists. They are published in a special book series "Plenarvorträge", sent to all members of the DPG. Smaller Sessions deal with special topics and include lectures presented by invited speakers as well as a limited number of contributed papers. An Evening Meeting is dedicated to an informal conversation between students and elder physicists.

On the last day of the Conferences of Physicists and the Spring Meetings special Lectures for Physics Teachers are held. Such lectures are organized also at the Spring Meetings of the Regional Branches.

The DPG also sponsors common meetings with other societies. An example of this is the European Meeting "Semiconductor Device Research" taking place in Munich, 24-27 March 1969. It is organized in co-operation with Region 8 of the Institute of Electrical and Electronics Engineers (IEEE, USA) and two German Societies : the Society of Electrical Engineers (VDE, Verband Deutscher Elektrotechniker) and the Society of Communication Engineers (NTG, Nachrichtentechnische Gesellschaft). Summer Schools are also sponsored, but these are organized by the Professional Groups or Special Divisions. A centre for such courses is planned.

The DPG owns two journals: the "Verhandlungen der DPG", an informative bulletin for the members of the Society, and the "Physikalische Berichte", the German abstract journal.

Every year the DPG awards the Max-Planck Medal to a theoretical physicist. In 1968 the medal was awarded to Walter Heitler, Zurich. The yearly Prize of the DPG (Physikerpreis), which includes a gift of money, is intended to draw public attention to an excellent young physicist.

\section{European \\ Molecular Biology Conference}

In a field of research which has become one of the major growth points of science, and in which physics is intimately involved, a new step in European co-operation has been agreed. On 13 February 1969 at a ceremony held at the Meyrin Laboratory of the European Organization for Nuclear Research (CERN) near Geneva, twelve nations signed the agreement to set up a "European Molecular Biology Conference" Austria, Denmark, Federal Republic of Germany, France, Greece, Italy, Netherlands, Norway, Spain, Sweden, Switzerland, United Kingdom.

The agreement, which is initially for 5 years, will come into force when it has been ratified by that number of States which represents at least $70 \%$ of the total contributions according to an agreed scale. The scale is based upon the net national revenues of the thirteen nations that make up the membership of CERN

The signatures are the fruit of more than two years of discussion and negotiation stimulated particularly by the Swiss Federal Government. The Conference will be generally known by its French initials (Conférence Européenne de Biologie Moléculaire). It will provide for the pooling of financial resources contributed by member governments using as principal agent the European Molecular Biology Organization (EMBO).

EMBO was set up in 1963 by a number of leading European molecular biologists. It has been supported up to now by a number of private sources, notably the Volkswagen Foundation and Interphama and by the Government of Israel.

CEBM will continue and extend the collaborative work begun by EMBO, the principal objectives being expressed in the Convention of the Conference as follows :

a) provision for training, teaching and research scholarships;

b) assistance to universities and other institutions of higher learning that wish to receive visiting professors

c) the establishment of programmes of courses and the organization of study meetings, co-ordinated with the programmes of universities and other institutions of higher learning and research. 